Supporting Information

\title{
$2,3-{ }^{13} \mathrm{C}$ labelling of aromatic residues - getting a head start in the MAS-NMR assignment of membrane proteins
}

Matthias Hiller, Victoria A. Higman, Stefan Jehle, Barth-Jan van Rossum,

Werner Kühlbrandt and Hartmut Oschkinat

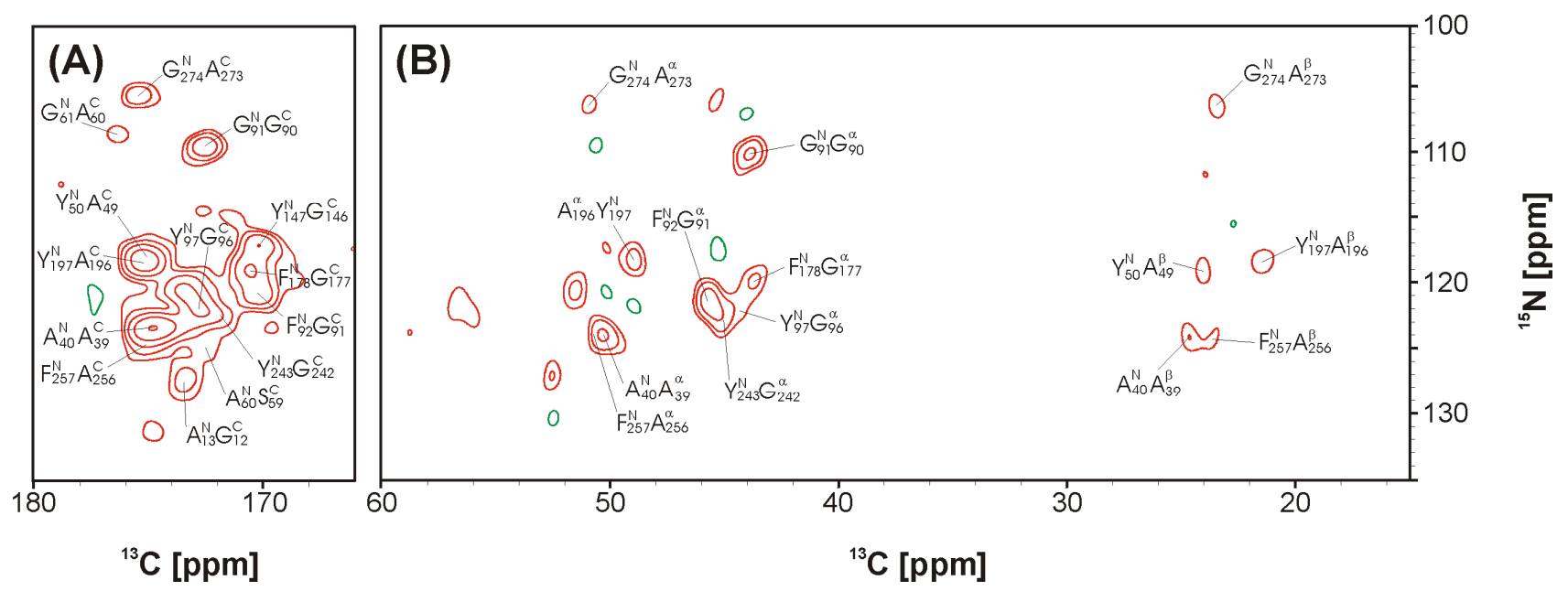

Supplementary Figure 1. (A) Carbonyl region of a REDOR spectrum of GAFY-OmpG recorded at $400 \mathrm{MHz}$ and $280 \mathrm{~K}$ with a REDOR mixing time of $1 \mathrm{~ms}$. (B) Aliphatic region of an NCOCX spectrum of GAFY-OmpG recorded at $400 \mathrm{MHz}$ and $280 \mathrm{~K}$ with a mixing time of $50 \mathrm{~ms}$. Resonance assignments are indicated. 


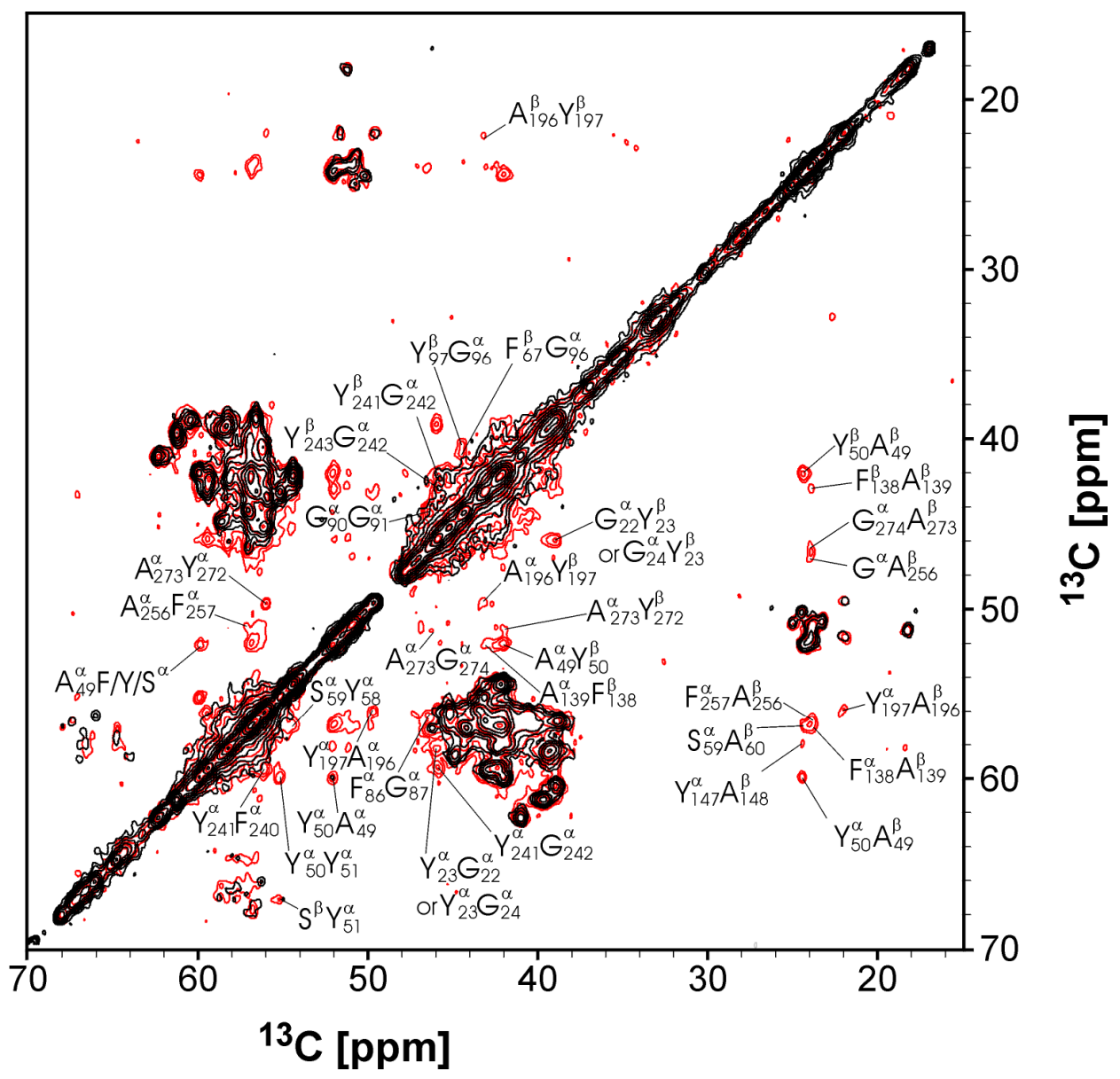

Supplementary Figure 2. Overlay of ${ }^{13} \mathrm{C}-{ }^{13} \mathrm{C}$ PDSD spectra of GAFY-OmpG recorded at $900 \mathrm{MHz}$ and $280 \mathrm{~K}$ with mixing times of $20 \mathrm{~ms}$ (black) and $700 \mathrm{~ms}$ (red). Assigned inter-residue cross-peaks are labeled. 

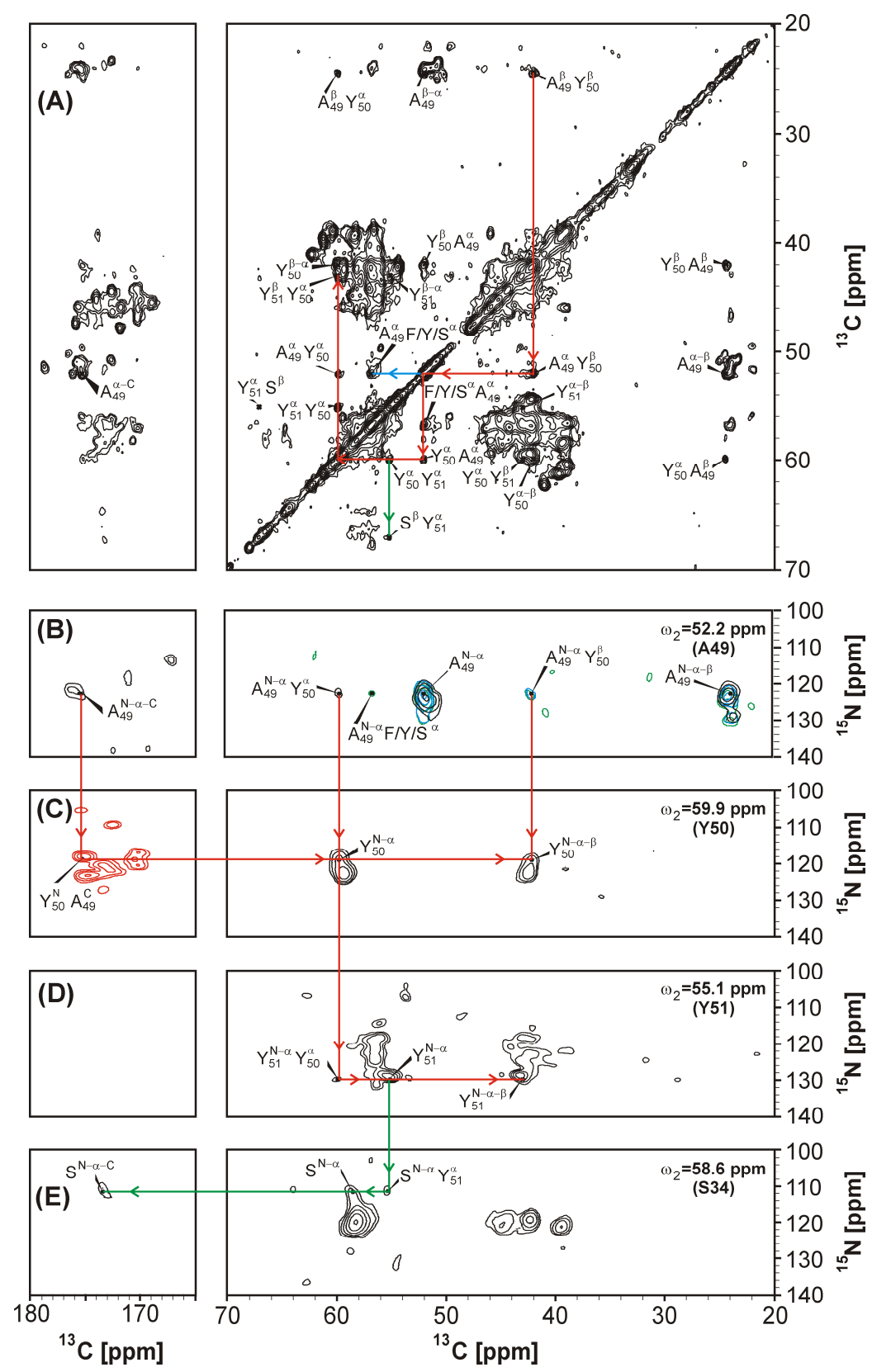

Supplementary Figure 3. Illustration of the assignment of the OmpG A49-Y50-Y51 motif using spectra recorded on Ompg-GAFY. (A) ${ }^{13} \mathrm{C}-{ }^{13} \mathrm{C}$ PDSD spectrum (500 ms). Sequential cross-peak connections can be traced from A49 $\alpha-Y 50 \beta$ to $Y 50 \alpha-A 49 \alpha, Y 50 \alpha-$ $Y 51 \alpha$ and $Y 50 \alpha-Y 51 \beta$ (red lines). Additional cross-strand links can be found from $A 49 \alpha$ to a $F / Y / S \alpha$ (blue line) and from $Y 51 \alpha$ to a $S \beta$ (green line). (B) $2 D$ planes at the $A 49 \alpha$ frequency of NCACX spectra (300 ms (black), $300 \mathrm{~ms}$ (blue) and $500 \mathrm{~ms}$ (green)). Crosspeaks to $\mathrm{Y} 50 \alpha, \mathrm{Y} 50 \beta$ and the $\mathrm{F} / \mathrm{Y} / \mathrm{S} \alpha$ are visible at a variety of different mixing times. (C) The aliphatic region of a 2D plane at the $Y 50 \alpha$ frequency of the NCACX spectrum (300 $\mathrm{ms}$ ), and the carbonyl region of the REDOR spectrum (1 ms). A cross-peak in the REDOR spectrum connects $A 49 C^{\prime}$ with Y50N. (D) A 2D plane at the Y51 $\alpha$ frequency of the NCACX (300 ms). A cross-peak to $Y 50 \alpha$ is visible. (E) A 2D plane at a S $\alpha$ frequency of the NCACX spectrum (500 ms). Green lines show the cross-strand link from the $S \alpha$ to its $\beta$ and $C^{\prime}$ and to $Y 51 \alpha$. 

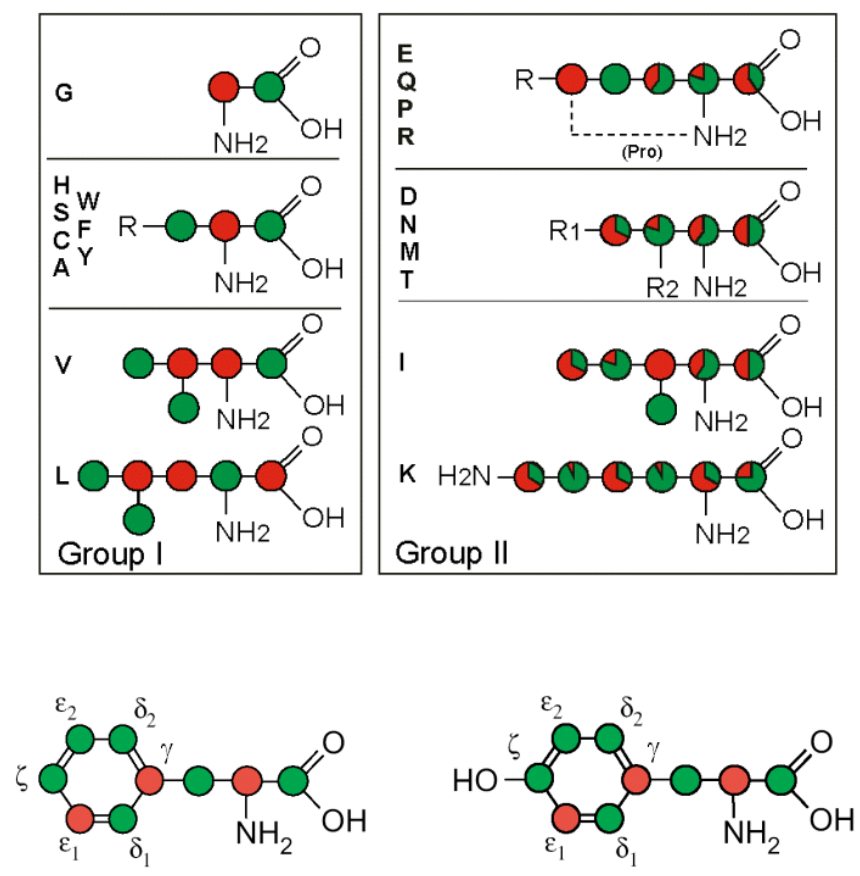

Phe $\gamma=137.4 \mathrm{ppm}$

Tyr $\gamma=128.8 \mathrm{ppm}$

Supplementary Figure 4. Schematic representation of the effective $\left[{ }^{13} \mathrm{C}\right]$-enrichment of amino acids, as obtained by protein expression in $E$. coli BL21 (DE3). ${ }^{1}$ Colors correspond to the $\left[{ }^{13} \mathrm{C}\right]$-labeling obtained by growth on $\left[1,3-{ }^{13} \mathrm{C}\right]$-glycerol (green) or [2$\left.{ }^{13} \mathrm{C}\right]$-glycerol (red) as the sole carbon source. In cases with mixed labeling, the percentage label (as estimated by solution NMR for $\alpha$-spectrin $\mathrm{SH} 3)^{1}$ from $\left[2-{ }^{13} \mathrm{C}\right]-$ glycerol and $\left[1,3^{-13} \mathrm{C}\right]$-glycerol for a particular atom is represented using relative red/green coloring. The average chemical-shift values for the $\mathrm{C} \gamma$ of Phenylalanine and Tyrosine are indicated (taken from the BMRB-Database). 
Supplementary Table 1. Resonance List

\begin{tabular}{|c|c|c|c|c|c|c|}
\hline & & $\mathrm{N}$ & $\mathrm{CO}$ & $\mathrm{C} \alpha$ & $C \beta$ & $C_{\gamma}$ \\
\hline G & 12 & & 173.2 & 47.3 & 2 & $\quad 1$ \\
\hline$A$ & 13 & 128.0 & & 50.9 & 23.5 & $D_{2}$ \\
\hline $\mathrm{N}$ & 38 & & 171.1 & & 41.9 & \\
\hline$A$ & 39 & 120.5 & 174.9 & 50.4 & 24.6 & 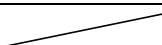 \\
\hline$A$ & 40 & 124.0 & 175.9 & 50.8 & 23.7 & 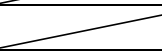 \\
\hline $\mathrm{N}$ & 41 & 120.9 & & 53.8 & 42.0 & \\
\hline $\mathrm{L}$ & 48 & & 175.9 & & 46.6 & 28.5 \\
\hline A & 49 & 122.4 & 175.3 & 51.7 & 24.0 & 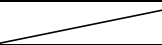 \\
\hline$Y$ & 50 & 119.0 & 173.6 & 59.6 & 41.8 & 128.8 \\
\hline $\mathrm{Y}$ & 51 & 129.2 & & 54.9 & 42.8 & 128.2 \\
\hline $\bar{Y}$ & 58 & 119.6 & & 54.2 & 41.9 & 130.6 \\
\hline$S$ & 59 & 120.0 & 172.6 & 56.5 & 67.2 & W \\
\hline$A$ & 60 & 125.6 & 176.3 & 49.8 & 24.1 & $D_{2}$ \\
\hline $\mathrm{G}$ & 61 & 109.0 & 175.7 & 49.8 & $\longrightarrow$ & . \\
\hline $\mathrm{F}$ & 86 & 119.2 & & 55.9 & 44.8 & 138.9 \\
\hline G & 87 & 106.0 & 175.1 & 46.2 & 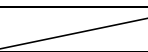 & 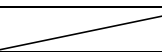 \\
\hline $\mathrm{L}$ & 88 & 123.9 & & 54.2 & & \\
\hline$T$ & 89 & & 171.3 & & 70.9 & \\
\hline $\mathrm{G}$ & 90 & 113.7 & 172.4 & 44.0 & 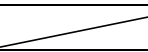 & 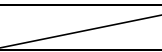 \\
\hline $\mathrm{G}$ & 91 & 109.7 & 170.0 & 46.0 & 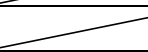 & 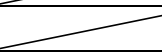 \\
\hline $\mathrm{F}$ & 92 & 121.6 & & 56.0 & 43.7 & 138.8 \\
\hline$Y$ & 95 & 119.0 & 170.9 & 57.8 & 42.1 & 130.5 \\
\hline G & 96 & 114.3 & 172.7 & 44.2 & $\longrightarrow$ & 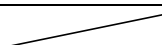 \\
\hline$Y$ & 97 & 122.2 & & 56.1 & 40.2 & \\
\hline $\mathrm{T}$ & 107 & & 173.5 & & 70.1 & \\
\hline A & 108 & 129.1 & 172.3 & 50.4 & 22.9 & \\
\hline $\mathrm{N}$ & 109 & 117.0 & & 53.6 & & \\
\hline $\mathrm{F}$ & 138 & 121.7 & & 56.5 & 42.6 & 140.2 \\
\hline$A$ & 139 & 121.2 & 175.8 & 51.6 & 23.7 & $\sqrt{2}$ \\
\hline $\mathrm{T}$ & 144 & & 176.8 & & 69.5 & \\
\hline$T$ & 145 & 109.7 & 178.3 & 62.4 & 69.3 & 22.4 \\
\hline G & 146 & 118.3 & 169.9 & 44.9 & 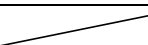 & $P_{2}$ \\
\hline$Y$ & 147 & 117.7 & 175.2 & 57.6 & 41.5 & 130.3 \\
\hline$A$ & 148 & 123.5 & 175.0 & 51.7 & 24.0 & 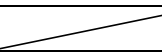 \\
\hline G & 177 & 113.8 & 170.4 & 43.7 & 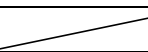 & 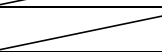 \\
\hline $\mathrm{F}$ & 178 & 119.3 & & 56.6 & 42.0 & 139.1 \\
\hline$A$ & 196 & 125.1 & 174.9 & 49.3 & 21.7 & P \\
\hline$Y$ & 197 & 118.3 & & 55.7 & 42.9 & 128.7 \\
\hline $\mathrm{F}$ & 240 & & & 55.8 & & \\
\hline $\bar{Y}$ & 241 & 122.8 & & 59.1 & 41.9 & 130.5 \\
\hline G & 242 & 112.5 & 171.6 & 45.6 & 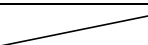 & P \\
\hline$Y$ & 243 & 123.3 & & 59.1 & 42.6 & 132.4 \\
\hline$A$ & 256 & 128.9 & 175.3 & 50.7 & 23.6 & \\
\hline $\mathrm{F}$ & 257 & 124.3 & & 44.0 & 56.6 & \\
\hline $\mathrm{Y}$ & 272 & & & & 41.6 & \\
\hline$A$ & 273 & 129.6 & 175.2 & 51.0 & 23.4 & $\pi$ \\
\hline$G$ & 274 & 106.2 & 170.6 & 45.8 & ${ }_{2}$ & \\
\hline
\end{tabular}




\section{Sample preparation}

Selectively labeled samples of OmpG were prepared in a manner similar to that described earlier ${ }^{2}$ with the following changes: Expression was carried out following the protocol of Marley at al., 2001. ${ }^{3}$ In this method cell mass is predominately grown on unlabeled rich media allowing rapid growth to high cell densities. The general protocol is as follows: cells were grown in 4 liters of $L B$ at $37^{\circ} \mathrm{C}$ with shaking at $180 \mathrm{rpm}$. Upon reaching optical cell densities at $600 \mathrm{~nm}$ of $\sim 0.5$, the cells were pelleted by $15 \mathrm{~min}$ centrifugation at $5000 \times \mathrm{g}$. The cells were then washed and pelleted using a $1 \times \mathrm{M} 9$ salt solution, to exclude all nitrogen and carbon sources. The cell pellet was resuspended in isotopically labeled minimal media (using volumes optimized in small-scale experiments) and then incubated to allow the recovery of growth and clearance of unlabeled metabolites. Protein expression was induced after $1 \mathrm{~h}$ by addition of isopropylthio- $\beta$ - $D$-galactoside at a concentration of $1 \mathrm{mM}$. After a $4 \mathrm{~h}$ incubation period the cells were harvested.

For the OmpG-GAFY sample, the resulting pellet was resuspended in 2 liters of M9 minimal medium containing $200 \mathrm{mg}$ of each labeled and unlabelled amino acid, $2 \mathrm{~g}$ of glucose and $0.5 \mathrm{~g}$ of $\mathrm{NH}_{4} \mathrm{Cl}$ per liter of culture.

When using glycerol as the sole carbon source, the cells were resuspended in 2 liters of M9 minimal medium containing $\left[2-{ }^{13} \mathrm{C}\right]$ - or $\left[1,3-{ }^{13} \mathrm{C}\right]$-labeled glycerol $(2 \mathrm{~g} / \mathrm{l})$ as the sole carbon source and $\left[{ }^{15} \mathrm{~N}\right]-\mathrm{NH}_{4} \mathrm{Cl}(0.5 \mathrm{~g} / \mathrm{l})$ as the sole nitrogen source.

In the case of uniform $\left[{ }^{13} \mathrm{C}^{15} \mathrm{~N}\right]-\mathrm{OmpG}$, we resuspended the cells in just 1 liter of M9 minimal medium containing $\left[{ }^{13} \mathrm{C}\right]$-glucose $(2 \mathrm{~g} / \mathrm{l})$ as the sole carbon source and $\left[{ }^{15} \mathrm{~N}\right]$ $\mathrm{NH}_{4} \mathrm{Cl}(0.5 \mathrm{~g} / \mathrm{l})$ as the sole nitrogen source.

Protein purification, refolding and 2D crystallization were carried out as described previously. ${ }^{2}$

In small scale experiments we concentrated the cells four- and two-fold, without a decrease in OmpG expression, using glucose and glycerol as the sole carbon sources, respectively. Using glycerol, a four-fold concentration of the cells leads to a decreased expression level of OmpG. This is due to the fact that glycerol has to be converted to glyceraldehyde-3-phophate by the action of an ATP-dependent kinase, which can also phosphorylate dihydroxyacetone. The kinase has the unusual feature of being non- 
competitively inhibited by fructose 1,6-bisphosphate and the enzyme III Glc, which leads to the prevention of glycerol consumption. ${ }^{4}$ In supplementary table 2 the expression yields are compared between the standard and modified expression protocols. Using glucose as the sole carbon source the amount of biomass was increased four fold compared to the standard expression protocol. In addition, the yield of refolded uniformly $\left[{ }^{13} \mathrm{C},{ }^{15} \mathrm{~N}\right]$-labeled OmpG is five times higher. Using $\left[1,3-{ }^{13} \mathrm{C}\right]-$ or $\left[2-{ }^{13} \mathrm{C}\right]$-glycerol as the sole carbon source we obtained yields three times higher compared to the standard protocol. [GAFY, $\left.{ }^{15} \mathrm{~N}\right]-\mathrm{OmpG}$ was only produced using the modified protocol.

In our lab a number of different recombinant proteins have been expressed following the protocol of Marley et al. and in all cases improved protein yields were observed at reduced isotope costs. 
Supplementary Table 2. Comparison of expression yields using standard and modified expression protocols.

\begin{tabular}{|c|c|c|c|c|c|c|c|}
\hline & \multicolumn{2}{|c|}{$\mathrm{u}-\left[{ }^{13} \mathrm{C}_{1}{ }^{15} \mathrm{~N}\right]-\mathrm{OmpG}$} & \multicolumn{2}{|c|}{$\left[1,3-{ }^{13} \mathrm{C}_{1}{ }^{15} \mathrm{~N}\right]-\mathrm{OmpG}$} & \multicolumn{2}{|c|}{$\left[2-{ }^{13} \mathrm{C},{ }^{15} \mathrm{~N}\right]-\mathrm{OmpG}$} & \multirow{2}{*}{$\begin{array}{c}{[\mathrm{GAFY},} \\
\left.{ }^{15} \mathrm{~N}\right]-\mathrm{OmpG} \\
\text { modified }\end{array}$} \\
\hline & standard & modified & standard & modified & standard & modified & \\
\hline carbon source $[\mathrm{g} / \mathrm{L}]$ & $2.0_{\mathrm{Glc}}$ & $2.0_{\mathrm{Glc}}$ & $2.0_{\mathrm{Gly}}$ & $2.0_{\mathrm{Gly}}$ & $2.0_{\mathrm{Gly}}$ & $2.0_{\mathrm{Gly}}$ & $2.0_{\mathrm{AS}}$ \\
\hline biomass [g/L] & 2.9 & 8.7 & 1.8 & 3.2 & 1.7 & 3.3 & 3.9 \\
\hline $\begin{array}{l}\text { Refolded OmpG } \\
\text { [mg/L culture }]\end{array}$ & 16.8 & 86 & 9.9 & 31 & 9 & 27 & 59 \\
\hline
\end{tabular}

AS = amino acid (labeled and unlabeled)

Glc $\quad=\left[{ }^{13} \mathrm{C}\right]$-glucose

Gly $=\left[1,3-{ }^{13} \mathrm{C}\right]$ - or $\left[2-{ }^{13} \mathrm{C}\right]$-glycerol 


\section{Solid-state MAS-NMR experiments}

2D ${ }^{13} \mathrm{C}-{ }^{13} \mathrm{C}$ spectra of OmpG using the proton-driven spin-diffusion (PDSD) $)^{5}$ mixing scheme were recorded on a Bruker AV900 $\mathrm{MHz}$ standard bore spectrometer at $280 \mathrm{~K}$ with a MAS frequency $\omega_{\mathrm{R}} / 2 \pi$ of $13 \mathrm{kHz}$. Magnetization was transferred from ${ }^{1} \mathrm{H}$ to ${ }^{13} \mathrm{C}$ with a ramped $\mathrm{CP}$ of $1 \mathrm{~ms}$ and spinlock field strengths of $\sim 58 \mathrm{kHz}$ for the ${ }^{1} \mathrm{H}$ and $\sim 73 \mathrm{kHz}$ for the ${ }^{13} \mathrm{C}$ ramp. PDSD mixing times of between 20 and $700 \mathrm{~ms}$ in combination with DARR ${ }^{6}$ were chosen and SPINAL64 ${ }^{7}$ was applied for proton decoupling (90-95 kHz). 128 scans per increment were collected, with an effective evolution time of $6 \mathrm{~ms}$ in the indirect dimension. One 2D data set was thus recorded in 3 days.

The comparison between the 2D ${ }^{13} \mathrm{C}-{ }^{13} \mathrm{C}$ PDSD and dipolar recoupling enhancement through amplitude motion (DREAM) (1,9 $^{2}$ spectra for OmpG-GAFY and OmpG-uni was conducted on a Bruker AV900 MHz standard bore spectrometer at $280 \mathrm{~K}$ with a MAS frequency $\omega_{\mathrm{R}} / 2 \pi$ of $13 \mathrm{kHz}$ and $3.2 \mathrm{~mm}$ rotor size. Magnetization was transferred from ${ }^{1} \mathrm{H}$ to ${ }^{13} \mathrm{C}$ with a ramped $\mathrm{CP}$ of $500-750 \mu \mathrm{s}$ (optimized for maximum aromatic $\mathrm{C} \alpha$ and $\mathrm{C} \beta$ signals) and spinlock field strengths of $\sim 54 \mathrm{kHz}$ for ${ }^{1} \mathrm{H}$ and $\sim 66 \mathrm{kHz}$ for the ${ }^{13} \mathrm{C}$ ramp. The DREAM sequence was applied for $1.5 \mathrm{~ms}$ using a $85 \%$ ramp and optimized for the aromatic $C \alpha-C \beta$ cross-peaks. PDSD mixing times of 20 ms were used - shorter (10 ms) and longer (35 ms) mixing times did not increase the aromatic $\mathrm{C} \alpha-\mathrm{C} \beta$ signal intensities. SPINAL64 ${ }^{7}$ proton decoupling at $90 \mathrm{kHz}$ was applied. 80 scans per increment were collected, with $820 \mathrm{t}_{1}$ increments and an effective evolution time of $6.5 \mathrm{~ms}$ in the indirect dimension. The measurement time was around 55 hours per experiment.

One-bond carbon-carbon scalar couplings (which range up to about $55 \mathrm{~Hz}$ for the glycines) are present in the OmpG-GAFY carbon-carbon correlation spectra leading to large agglomerates of cross peaks. Maximum resolution of these clusters was possible by recording the spectra on a $900 \mathrm{MHz}$ spectrometer. Other decoupling techniques were not considered.

3D NCACX experiments were performed on a Bruker $400 \mathrm{MHz}$ wide bore spectrometer at $280 \mathrm{~K}$ as described by Castellani et al., 2003. ${ }^{9}$ Following ${ }^{1} \mathrm{H}$ excitation, a ramped CP contact of 2 ms between ${ }^{1} \mathrm{H}$ and ${ }^{15} \mathrm{~N}$ created the initial ${ }^{15} \mathrm{~N}$ magnetization; spin lock fields of $55 \mathrm{kHz}$ for ${ }^{1} \mathrm{H}$ and $43 \mathrm{kHz}$ for the ${ }^{15} \mathrm{~N}$ ramp were applied. Following the evolution of nitrogen, adiabatic CP was employed to selectively transfer magnetization from ${ }^{15} \mathrm{~N}$ to ${ }^{13} \mathrm{C}$ with RF powers of 15 and $23 \mathrm{kHz}$, respectively. The amide signals and the ${ }^{13} \mathrm{C} \alpha$-signal 
were irradiated on-resonance. The ${ }^{13} \mathrm{C}$ evolution period was followed by a PDSD mixing scheme lasting 20, 100, 200, 300 or $500 \mathrm{~ms}^{4}$ During all evolution periods, proton decoupling was applied, using SPINAL64 (90-95 kHz). ${ }^{6}$ The 3D data sets were recorded using evolution times of $6.8 \mathrm{~ms}$ in $t_{1}$ and $6.4 \mathrm{~ms}$ in $t_{2}$. Each FID was averaged from 96 scans yielding a total measurement time of $\sim 41 / 2$ days per spectrum.

A 2D NCOCX spectrum ${ }^{10}$ was recorded in a similar way on a Bruker $400 \mathrm{MHz}$ wide bore spectrometer at $280 \mathrm{~K}$. Following the evolution of nitrogen, adiabatic CP was employed to selectively transfer magnetization from ${ }^{15} \mathrm{~N}$ to ${ }^{13} \mathrm{C}$ with $\mathrm{RF}$ powers of 15 and $23 \mathrm{kHz}$, respectively. The amide signals and the ${ }^{13} \mathrm{C}^{\prime}$-signal were irradiated on-resonance. The ${ }^{13} \mathrm{C}$ evolution period was followed by a PDSD mixing scheme (50 ms). During all evolution periods, proton decoupling was applied, using SPINAL64 (90-95 kHz). ${ }^{6} 2048$ scans per increment were collected, with an effective evolution time of $6.4 \mathrm{~ms}$ in the indirect dimension. The data set was thus recorded in $4 \frac{1}{2}$ days.

A TEDOR transfer scheme was used for the ${ }^{13} \mathrm{C}-{ }^{15} \mathrm{~N}$ correlation experiment on a Bruker $400 \mathrm{MHz}$ wide bore spectrometer at $280 \mathrm{~K} \cdot{ }^{11,12}$ The REDOR mixing time ${ }^{13}$ was $1 \mathrm{~ms}$ for one bond transfer at a spinning frequency $\omega_{\mathrm{R}}=8 \mathrm{kHz}$. Typical ${ }^{15} \mathrm{~N} \pi$-pulse lengths during the REDOR mixing for OmpG were $13 \mu \mathrm{s}$. After $t_{1}$-evolution of ${ }^{15} \mathrm{~N}$, a $z$-filter was used to retain rotor synchronization by compensating pulse durations. ${ }^{11,12}$ During $t_{1}$-evolution, acquisition and REDOR-mixing, SPINAL64 decoupling at $88 \mathrm{kHz}$ was used for heteronuclear decoupling. ${ }^{6}$ The $t_{1}$-increment was chosen to be $1 / \omega_{\mathrm{R}}=125 \mu \mathrm{s}$. The total indirect acquisition time was 6 ms.

Data were processed using XWINNMR 2.6 (Bruker, Karlsruhe, Germany) and Topspin 1.3 (Bruker, Karlsruhe, Germany). They were subsequently analyzed using Sparky 3.1 (T. D. Goddard \& D. G. Kneller, University of California, USA) and CCPN Analysis 1.0. ${ }^{15}$ 


\section{Reference List}

(1) Castellani, F.; van Rossum, B.; Diehl, A.; Schubert, M.; Rehbein, K.; Oschkinat, H. Nature 2002, 420, 98-102.

(2) Hiller, M.; Krabben, L.; Vinothkumar, K. R.; Castellani, F.; van Rossum, B. J.; Kuhlbrandt, W.; Oschkinat, H. Chem.BioChem. 2005, 6, 1679-1684.

(3) Marley, J.; Lu, M.; Bracken, C. J.Biomol.NMR 2001, 20, 71-75.

(4) Lin, E. Dissimilatory Pathways for Sugars, Polyols and Carboxylates; In Escherichia coli and Salmonella. Cellular and Molecular Biology; Neidhardt, F., ed. ASM Press: Washington, D.C., 1996; pp 307-342.

(5) Szeverenyi, N. M.; Sullivan, M. J.; Maciel, G. E. J.Magn.Reson. 1982, 47, 462475.

(6) Takegoshi, K.; Nakamura, S.; Terao, T. Chem.Phys.Lett. 2001, 344, 631-637.

(7) Fung, B. M.; Khitrin, A. K.; Ermolaev, K. J.Magn.Reson. 2000, 142, 97-101.

(8) Verel, R.; Baldus, M.; Ernst, M.; Meier, B. H. Chem.Phys.Lett. 1998, 287, 421428.

(9) Verel, R.; Ernst, M.; Meier, B. H. J.Magn.Reson. 2001, 150, 81-99.

(10) Castellani, F.; van Rossum, B. J.; Diehl, A.; Rehbein, K.; Oschkinat, H. Biochem. 2003, 42, 11476-11483.

(11) Pauli, J.; Baldus, M.; van Rossum, B.; de Groot, H.; Oschkinat, H. Chem.Biochem. 2001, 2, 272-281.

(12) Hong, M.; Griffin, R. G. J.Am.Chem.Soc. 1998, 120, 7113-7114.

(13) Jaroniec, C. P.; Filip, C.; Griffin, R. G. J.Am.Chem.Soc. 2002, 124, 10728-10742.

(14) Gullion, T.; Schaefer, J. J.Magn.Reson. 1989, 81, 196-200.

(15) Vranken, W. F.; Boucher, W.; Stevens, T. J.; Fogh, R. H.; Pajon, A.; Llinas, P.; Ulrich, E. L.; Markley, J. L.; Ionides, J.; Laue, E. D. Prot.Struct.Funct.Bioinf. 2005, 59, 687-696. 